\title{
LEVELS OF USE OF SELECTED COMPONENTS OF THE COMPREHENSIVE BASIC NURSING PROGRAMME
}

\author{
NS Gwele
}

\begin{abstract}
Change in nursing education in South Africa has been characterised by the predominance of the use of powercoercive strategies to effect change. Changes in nursing curricula are legislated through the South African Nursing Council. The Comprehensive Basic Nursing Programme (CBNP) became mandatory for all institutions offering basic professional nurse preparation education programmes in this country in 1985.
\end{abstract}

This was a comparative descriptive study aimed at examining the levels of use of 47 nurse educators at four nursing colleges regarding their behaviours and skills in implementing four selected components of the CBNP. The components of the CBNP which formed the focus for this study were teaching to produce nurses capable of (a) rendering comprehensive health care, (b) nursing holistically, (c) thinking critically, and (d) leaming independently.

The Levels of Use diagnostic dimension of the Concerns Based Adoption Model (CBAM) developed by the CBAM staff (Hall \& Hord, 1987; Hall \& Loucks, 1977, Hord, 1987; Loucks, Newlove, \& Hall, 1975) was used as a guideline for designing the interview schedules for each of the four components of the CBNP. Data were collected by means of interviews using focused interview schedules designed by the researcher.

A large number of nurse educators were rated at or below mechanical Level of Use on teaching for $\mathrm{CHC}$ (n $=26$ ), and critical thinking ( $n=22$ ). More than half the nurse educators interviewed reported that they were comfortable with their behaviours and skills concerning teaching for holistic nursing and developing independence in learning.

\section{INTRODUCTION}

The passing of the 1985 regulations from the SA Nursing Council (R425 of 1985), resulted in two major changes in control of basic nursing education. Firstly the development of basic nursing curricula was transferred to individual nursing colleges at local level, although "basic" standards were laid down centrally. Secondly, basic nursing education became part of the country's post-secondary education system through university-college affiliation. Both of these developments had important ramifications for nursing education.

Based on the regulations and guidelines of the South African Nursing Council (SANC), each nursing college was to develop its own curriculum. The comprehensive basic nursing programme (CBNP) had cast nurse educators as professionals who could rebuild nurse education almost single handedly. When nurse educators were expected to implement the new programme, preparing them to do so was not a central concern. According to $V$ an der Merwe (1989, p. 37) the CBNP "expected every lecturer to understand and implement the totality of the curriculum". Centralised decision making assumed that the people responsible for the adoption and institutionalisation of the new policies would do so with the necessary willingness and expertise.

The need to evaluate this programme has been mentioned by a few authors (Rispel \& Motsei, 1988; Uys, 1991). Rispel and Motsei (1988. p. 16) proposed that, "the most obvious suggestion for future research (in nursing education) is an intervention study to evaluate the comprehensive four-year course".

Without discounting this call for evaluating the CBNP, it is believed that in order to evaluate outcomes of any educational innovation, it is vital to first determine whether the programme is being implemented, and if so, how. Several studies (Cameron, 1991; Hall \& Loucks, 1977; Ross, Luepker, Nelson, Saavedra, \& Hubbard, 1991) which used the Concerns Based Adoption Model (CBAM) to evaluate educational change reported on the importance of establishing levels of use before embarking on impact studies. Hall and Hord (1987) wamed that adoption of a particular innovation by an educational institution does not necessarily mean that every teacher in that institution is using the innovation.

This study aimed at investigating the process of adoption and implementation of the CBNP, with a view to better understand the consequences of legislated change in nursing education. Specifically, the following questions were asked:

(a) At what level are the behaviours and skills of nurse educators at nursing colleges in their implementation of selected components of the CBNP?, and

(b) Are there any differences in the levels of use of the four components of the CBNP by nurse educators at early and late adopter nursing colleges?

\section{LITERATURE REVIEW AND RELATED THEORY}

\section{THE CONCEPT OF CHANGE}

Debeauvais (1981, p. ix) noted that "an important feature of the 1970s was the unprecedented effort brought to bear on innovation and reform in the educational system". On a similar note, Hord (1987, p. 22) asserted that "more recently, the concept of change, now inextricably linked with its Siamese twin, progress, has become a philosophical comerstone of many industrial democracies, that see it as an almost automatic good, equating continual change with a seemingly inevitable progression toward perfection".

However, educational researchers and administrators, basing opinion on accumulated literature of implementation and outcomes of specific innovations, have come to realise that educational innovation cannot be pursued artitrarily. The last few decades have seen an evolution of change theories which has facilitated the study of change in educational institutions (Hord, 1987).

The dominance of top-down (power-coercive, empirical-rational) approaches to the implementation of change in nursing and nursing education has been documented by a 
number of authors (Filkins, 1986; Gibbs, 1991). This is not surprising. Nursing has always been and is currently managed according to an orthodox bureaucratic model. For instance, Uys (1991) attributed the lack of innovative educational programmes in nursing to (a) rigid interpretation and implementation of the South African Nursing Council (SANC) regulations, and (b) the influence of the bureaucratic system in which nursing education and nursing services operate. The emphasis on bureaucratic management has perpetuated the power-coercive strategy to the implementation of change in nursing. Sheehan (1990) warned that such an approach is not likely to be acceptable to most individuals who find themselves caught up in the demand to change.

\section{THEORETICAL FRAMEWORK}

The theoretical approach on which this study is based is the concerns-based adoption model (CBAM). The relevance of this model to the questions posed by this study is its emphasis on the process of implementation rather than the origin of change itself. In CBAM terms, whether change originates from the top or bottom is not really important in terms of whether positive change will or will not occur in educational institutions. Hord (1987, p. 14) writes that "The key to successful innovation is implementation; and the unwritten rules of implementation remain the same, whether approached from above or below". In nursing education, perhaps in the interest of maintaining standards, national education reforms will almost always originate from the top. The successful implementation of such reforms will be determined largely by whether or not the unwritten rules of implementation are adhered to or broken.

Hall, Wallace and Dosset (cited in Hord, 1987, p. 93) described the CBAM approach as "an empirically based conceptual framework which outlines the developmental process that individuals experience as they implement an innovation".

The CBAM approach is based on the belief that there is a set of developmental stages and levels teachers and others move through as they become increasingly skilled in using new programmes and procedures. One of the assumptions that underpin the CBAM approach is that change is a developmental process and it is believed that behaviours and skills related to an innovation tend to follow a certain developmental pattem (Hall \& Hord, 1987; Hord, 1987).

Based on these assumption the CBAM was developed. This conceptual model consists of four components. These include the (a) Stages of Concern (SoC), (b) Levels of Use (LoU),

(c) Innovation Configuration (IC), and (d) Intervention Taxonomy. For the purposes of this study, only the LoU dimension will be described.

\section{LEVELS OF USE (LoU) OF AN INNOVATION}

The LoU dimension focuses on peoples behaviours and skills with respect to the innovation. In the CBAM approach, analyzing whether an innovation is being used entails more than a simple yes or no dichotomous question. According to Hall and Hord (1987) the levels of use of an innovation include: LoU 0 (Non-use), LoU 1 (Orientation), LoU II (Preparation), LoU III (Mechanical use), LoU IVA (Routine use), LoU IVB (Refinement), LoU V (Integration), and LoU VI (Renewal).

\section{a) LoU 0: NON-USE}

At this level, the individual exhibits no behaviour related to the innovation at all. He or she is doing absolutely nothing toward being involved with the innovation (Hall \& Hord, 1987; Hall \& Loucks, 1977; Hord, 1987).

\section{b) LoU I: ORIENTATION}

At the Orientation LoU, the user is actively seeking information about the innovation. He or she is busy grappling with the innovation's value system as well as its demands upon the user and the user's system (Hall \& Hord, 1987; Hall \& Loucks, 1977; Hord, 1987).

\section{c) LoU II: PREPARATION}

The individual who is busy preparing for first time use is at the preparation LoU. He or she actually indicates intention to use the innovation. Typical behaviours include acquiring the materials and resources necessary for using (Hall, \& Hord, 1987; Hall \& Loucks, 1977; Hord, 1987).

\section{d) LoU III: MECHANICAL USE}

This is characteristic of an inexperienced and experimenting user. This kind of user is preoccupied with logistical aspects of the innovation. Demands of getting the materials needed, introducing the programme to students, making plans and time tables take much of the user's time. Hall and Hord (1987) maintained that people usually stay at this level for a long time and that it is possible that some people never get beyond the Mechanical Use level unless they receive sufficient training in how to use the innovation.

\section{e) LOU IVA: ROUTINE USE}

The LoU IVA user is comfortable with what he or she is doing and there is a feeling of having mastered the skills necessary to use the innovation. It is a period that follows the uncertainty and stress associated with the stage of mechanical use. More often than not, at this stage the user is relieved that he/she has finally reached a degree of stability and confidence with regard to the innovation. Hord (1987, p. 113) observed that "this stability, coming on the heels of a change and stress fulfils a crucial function for most people. Regardless of what they do subsequently, almost everyone will need some period of IVA use before they will be ready to move forward".

\section{f) LoU IVB: REFINEMENT}

Based on knowledge of short-term and long-term consequences of the innovation, the user seeks to modify it, in order to maximise or improve its impact on the students. These modifications may affect the programme itself, or the way it is delivered, used, or managed. The behaviours and the activities of the user are no longer focused on helping himself or herself, but rather are directed at finding ways to help the students achieve something out of it (Hall \& Hord, 1987; Hord, 1987).

\section{g) LoU V: INTEGRATION}

Teachers at LoU V make a commitment to collaborate with other teachers in the use of the innovation. They are now comfortable and confident enough with the innovation to be able to share and explore aspects related to how the other teachers are using the innovation (Hall \& Hord, 1987; Hall \& Loucks, 1977; Hord, 1987).

\section{h) LoU VI: RENEWAL}

At this point it almost can be said that "the original innovation has already been outgrown" (Hord, 1987, p. 114). The renewing user is already seeking and making major modifications in the innovation, to the extent of even replacing it altogether.

\section{HYPOTHESES}

It was hypothesised that (a) the LoU of all four components of the CBNP for nurse educators would be at or above Routine use and that (b) nurse educators at nursing colleges where the programme was adopted earlier than it was legally necessary to adopt, will exhibit LoU at or above routine level of use, compared to nurse educators at late adopter colleges.

\section{DEFINITION OF TERMS}

NURSE EDUCATORS refers to individuals with a teaching assignment (classroom and clinical) at the four selected nursing colleges offering the four-year comprehensive basic nursing programme (CBNP).

LEVELS OF USE refer to behaviours and skills of nurse educators in relation to the implementation of the four components of the CBNP as measured by the focused levels of use interview schedules (one for each component of the CBNP) developed by the researcher based on the guidelines by Loucks, Newlove, and Hall (1975). 


\section{COMPREHENSIVE BASIC NURSING PROGRAMME (CBNP)}

The term CBNP refers to the four-year diploma in midwifery and nursing -general, psychiatric, and community health nursing mandated by the SANC in 1985.

\section{COMPONENTS OF THE CBNP}

The four components of the CBNP under study were teaching for producing nurses capable of (a) rendering comprehensive health care, (b) rendering holistic nursing (c) thinking critically, and (d) learning independently.

\section{TEACHING FOR COMPREHENSIVE HEALTH CARE (CHC)}

For the purposes of this study, teaching for producing nurses capable of rendering $\mathrm{CHC}$ was defined as a description of teaching/learning activities and lesson content incorporating the (a) preventive, (b) promotive, (c) curative, and (d) rehabilitative aspects of health and disease within the context of the clinical nursing disciplines. Specifically, does the interviewee describe how a particular health problem can be prevented, any descriptions of health maintenance behaviours, what to do once health has been impaired, as well as how to ensure that the individual and /client restores the maximum capability for functioning independently?

\section{TEACHING FOR HOLISTIC NURSING}

Because the concept of an individual as a holistic human being creates difficulties in terms of traditional research; to; reiterate Stevens's words (1979) it is of necessity that for the purposes of this study a holistic curriculum refers to teaching/learning activities and lesson content which take into account the biophysiological, psychological, sociological, and ethnic-cultural dimensions of health and disease. In essence the content of the lesson as described by the interviewee must explain how the above dimensions of health and disease interrelate. The ideal description was defined as that which dealt with all of these determinants of health and disease.

\section{TEACHING FOR CRITICAL THINKING}

Within the context of this study, teaching for critical thinking was defined as teaching and learning activities that called for (a) inference, (b) comparing, (c) analysis, (d) interpretation, and (e) evaluation. These thinking abilities had to be integrated within the subject content of nursing. That is, ability to teach for critical thinking was measured in terms of whether or not the interviewees' descriptions of their teaching/learning activities revealed attempts at involving the student in the teaching/learning process in a questioning and facilitating manner. Specifically, use of highly interactive strategies such as debates, seminars and discussions in teaching and learning was seen as indicative of teaching for critical thinking.

\section{TEACHING FOR INDEPENDENT LEARNING}

Teaching and learning activities aimed at developing independent learning skills were defined as those descriptions of teaching/learning activities which involved (a) use of a variety of leaming experiences which require the students to utilise information access skills, for example, library use, locate experts in a specific subject, and actual clinical experiences (case studies), (b) provision of an opportunity for the students to have some say in what is to be learned and when, and (c) use of self-evaluation by the students.

\section{EARLY ADOPTER COLLEGES}

These were colleges which had elected to adopt the CBNP before it was legally mandated for all nursing colleges in the country. Early adopter colleges for this study were colleges $A$ and $C$.

\section{LATE ADOPTER COLLEGES}

These were colleges which did not adopt the CBNP until it was legally required that they do so in order to continue offering programmes leading to registration for professional nursing and midwifery. These were colleges $B$ and $\mathbf{D}$.

\section{METHODS}

\section{SAMPLE AND SAMPLING PROCEDURE}

The sample for this study consisted of 47 purposely selected nurse educators. These interviewees were chosen from a cluster sample of four nursing colleges selected by timing of adoption of the CBNP and province of location. Two colleges were randomly selected, whereas two were conveniently selected because of failure to gain access to other randomly selected colleges.

Twelve (12) nurse educators per college were selected purposively on the basis of their involvement with teaching the CBNP at the time of data collection. One refused to participate in the study.

\section{INSTRUMENTATION AND DATA COLLECTION}

The researcher taped interviews with individual nurse educators $(n=47)$ at the four selected nursing colleges. The levels of use of the four components of the CBNP were assessed by means of a focused, open-ended interview. The LoU interview was based on a format designed by Loucks, Newlove, and Hall (1975). The interview schedule started with a specific question, for example. "Are you teaching your students such that they would be able to render comprehensive health care?" Depending on the respondent's answer, the interview shifted to different parts of the interview guide. Each of the branching questions was followed by a series of category questions, which required the nurse educators to desscribe actions they had taken or would be taking in the future.

The interviewees were required to give detailed descriptions of (a) their understanding of each of the four components of the CBNP, (b) what they were actually doing in implementing these components, (c) their plans for the future, (d) as well as whether they were sharing any of their experiences with colleagues. The interviewees were asked to relate their responses to their behaviours outside and inside the classroom.

Hall and Loucks (1977) reported that the inter-rater reliability for the $\mathrm{LoU}$ interview and rating procedures ranged from .87 to .96 on overall Level of Use. Correlation coefficients on validity ratings were reported at .98 and .65 (Hall \& Loucks: 1977). For the present study, the interview schedules were pretested and an agreement of $75 \%$ between an initial and second rating-conducted a week later was found. An interrator reliability of tho .74 was achieved. Content validity of the instruments was acceptable to five nurse educators (two principals of nursing colleges and three university lecturers involved in teaching the CBNP).

\section{LIMITATIONS OF THE STUDY}

Inability to gain access to the original randomly chosen nursing colleges in two provinces compromised the generalisability of the findings of this study. However, four colleges out of the 36 nursing colleges in the country represents an $11 \%$ sample. Secondly, in differentiating between early and late adopter colleges the study did not control for the fact that individuals are mobile in nature therefore there was minimal difference in the mean number of years teaching the CBNP for nurse educators at early and late adopter colleges. 
Table 1: The Average Number of Years of Teaching the CBNP for Nurse Educators by Colleges

\section{Nursing College \\ A \\ (Early Adopter)}

B

(Late Adopter)

C

(Early Adopter)

D

(Late Adopter)

\section{Mean No. of Years Teaching the CBNP}

4.0

3.7

3.4

3.4

\section{RESULTS}

The mean number of years teaching the CBNP for the 47 interviewees was $3.6(S D=2.1)$. The mean number of years of teaching the CBNP for nurse educators by college appears in Table 1.

\section{VARIATIONS IN LEVELS OF USE OF THE FOUR COMPONENTS OF THE CBNP BY NURSE EDUCATORS AT NURSING COLLEGES.}

Comparisons on $\mathrm{LoU}$ of the nurse educators in the implementation of each of the components of the CBNP were conducted by means of descriptive statistics.
Standard Deviation

1.91

\section{LEVELS OF USE ON TEACHING FOR CHC}

Except for nurse educators at nursing college $B$, levels of use for this component were mainly at or below mechanical use. At all four nursing colleges, a few nurse educators were in fact not teaching for producing nurses capable of rendering $\mathrm{CHC}(\mathrm{A}:=3 ; \mathrm{B}=1 ; \mathrm{C}=$ $3 ; D=4$ See Figure 1).

None of the nurse educators interviewed at nursing college $D$ was at Routine use, whereas there was only one nurse educator comfortable with own teaching and learning activities in relation to teaching for $\mathrm{CHC}$ at colleges $\mathrm{A}$ and $\mathrm{C}$.

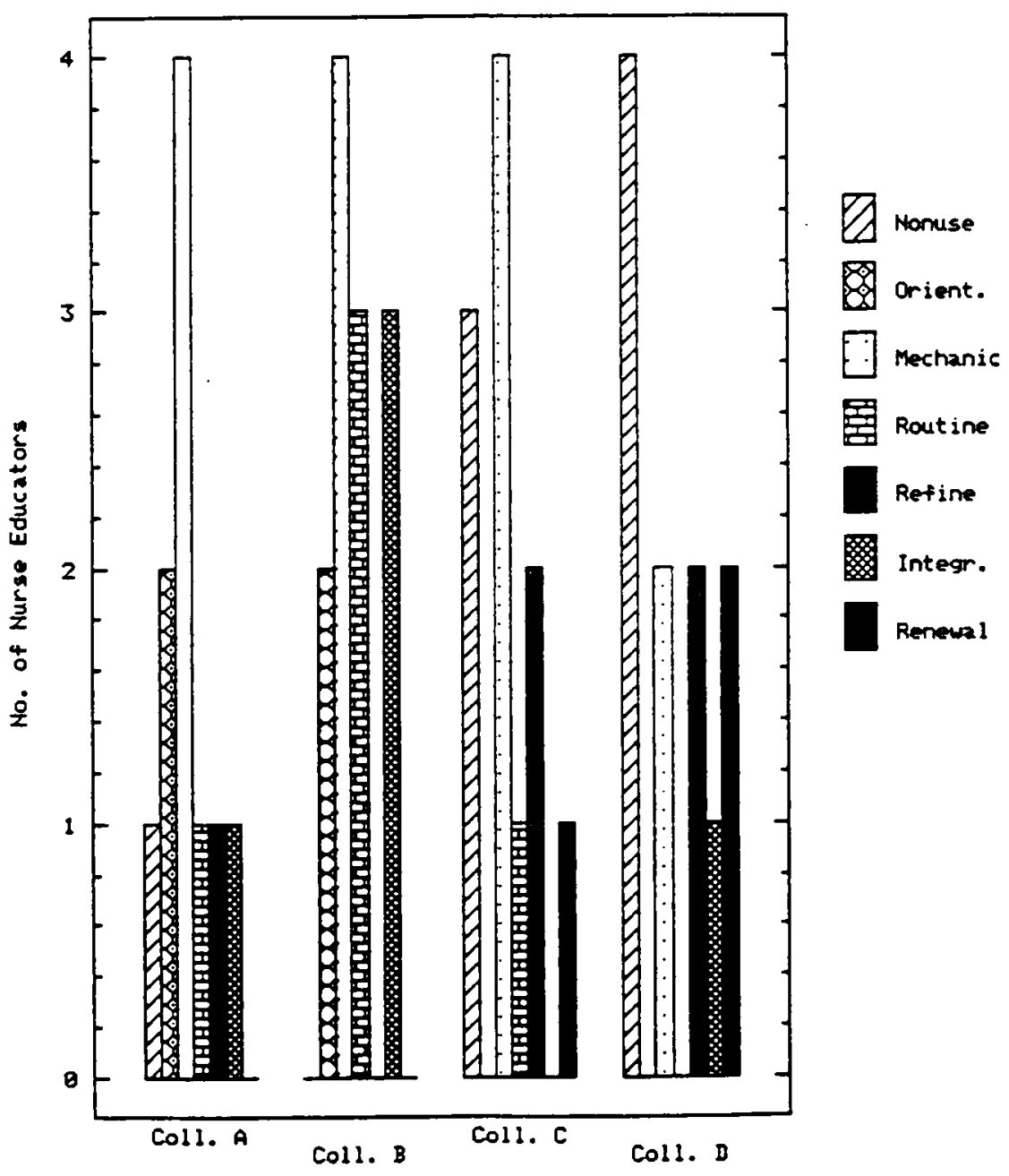

LEVELS OF USE ON TEACHING FOR HOLISTIC NURSING

Except for nurse educators at nursing college $\mathrm{B}$, LoU on teaching for holistic nursing were generally at or above routine use. Eight out of the 12 nurse educators interviewed at nursing college $B$ were rated at mechanical level of use, whereas, two nurse educators at nursing college A were not teaching for producing nurses capable of rendering holistic nursing at the time of data collection. These data are depicted in Figure 2.

\section{LEVELS OF USE ON TEACHING FOR CRITICAL THINKING}

At all the nursing colleges, except for nursing college A, $50 \%$ or more of the nurse educators were either comfortable with or busy modifying and changing their teaching and learning activities in relation to this component. These data appear on Figure 3. Two nurse educators, one at nursing college $A$ and one at nursing college $B$, were not teaching for critical thinking, whereas at nursing college $\mathrm{C}$ one nurse educator was preparing for initial use. In all, 22 nurse educators were rated at or below Mechanical Use.

\section{LEVELS OF USE ON TEACHING FOR DEVELOPING INDEPENDENT LEARNING SKILLS}

Developing independence in learning was the only component with which $50 \%$ or more of the nurse educators at each of the colleges felt comfortable. At nursing college $D$, nurse educators had begun coordinating and sharing their teaching and learning experiences with others in order to develop independence in learning, whereas at all the other three nursing colleges a few nurse educators were busy refining their behaviours and skills in relation to this component in order to maximise student outcomes. See Figure 4.

In order to answer the question on differences in LoU of nurse educators at nursing colleges by timing of adoption $2 \times 2$ Chi squares were computed. The LoU data were divided into two categories, that is, low and high levels of use. High levels of use were defined as levels of use at or above routine use.

It was predicted that nurse educators at nursing colleges where the programme was adopted earlier than it was legally necessary, would exhibit LoU at Routine use and above compared to those at late adopter colleges. No significant differences on LoU of nurse educators based on timing of adoption were found for any of the four components of the CBNP. 


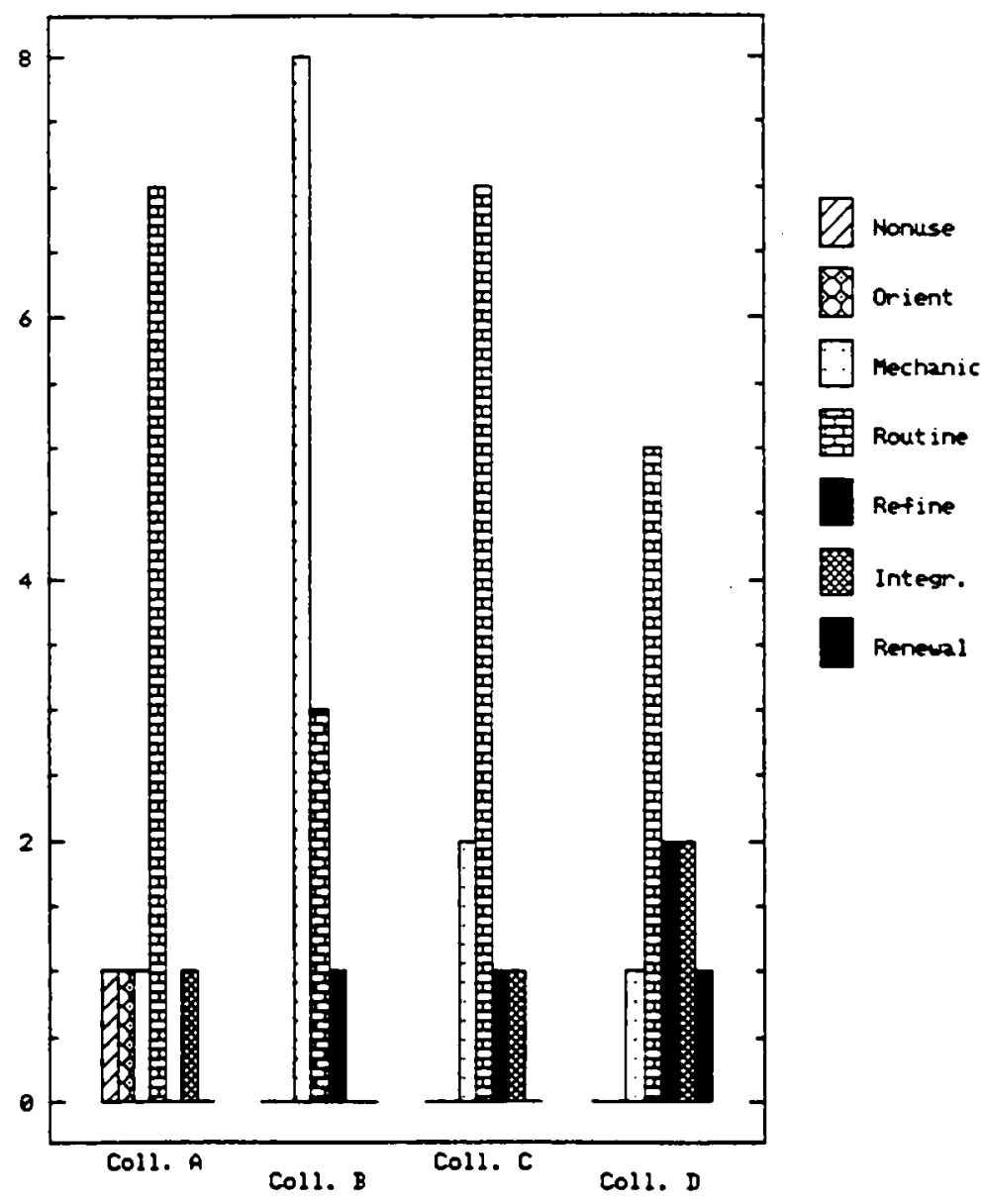

FIGURE 2: Variations between Colleges on Levels of Use on Teaching for Holistic Nursing

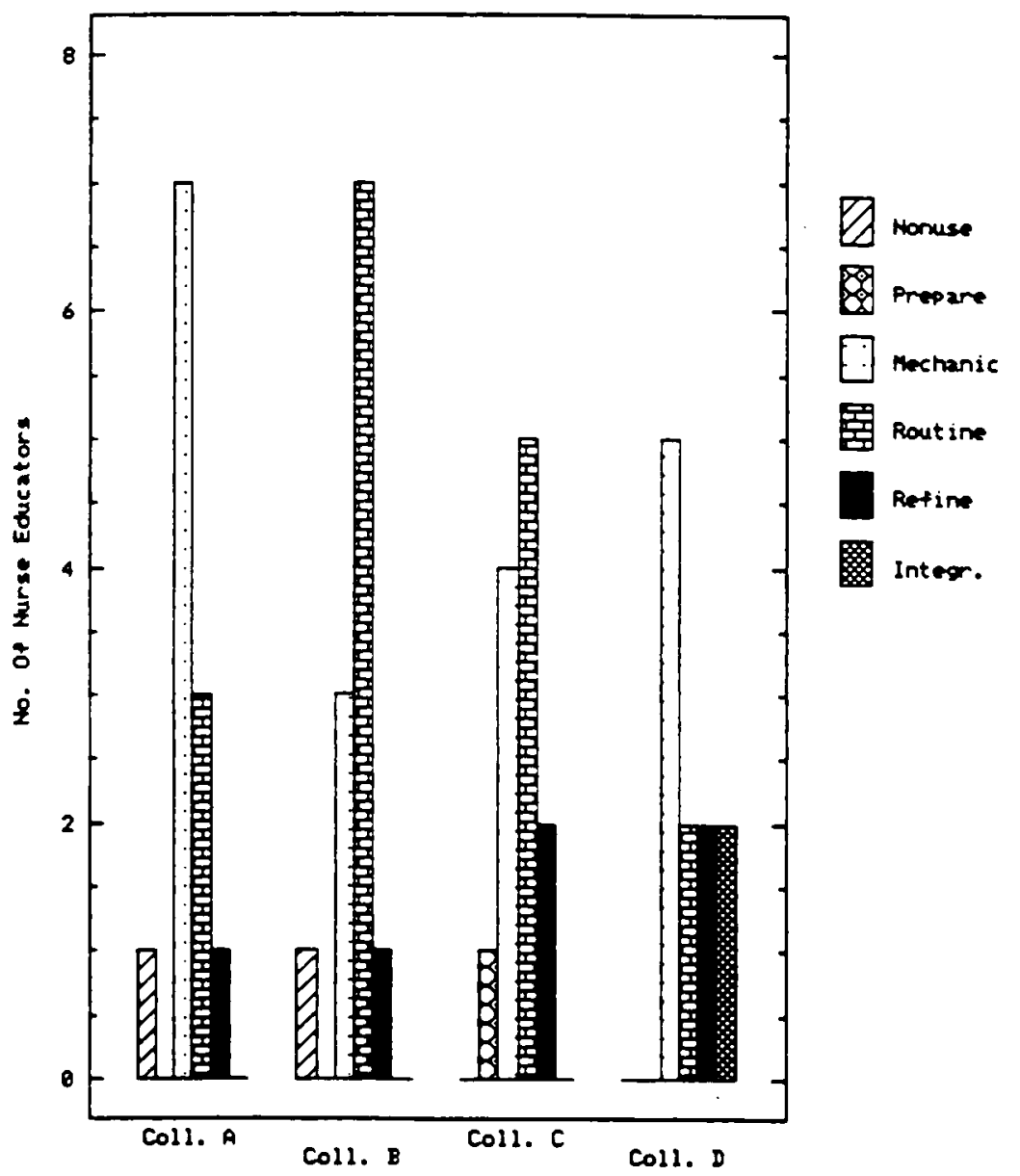

FIGURE 3: Variations between Colleges on Levels of Use on Teaching for Critical Thinking

\section{DISCUSSION}

No significant differences were found on LoU of nurse educators at early and late adopter colleges on all four components of the CBNP. It was expected that early adoption would be associated with levels of use at or above routine use. This expectation was based on the assumption that the nurse educators at early adopter colleges would be more experienced in teaching the CBNP. The failure of this study's results to account for variance between groups by timing of adoption can be attributed to the fact that the average number of years of teaching the CBNP was 3.7 and 3.5 for nurse educators at early and late adopter colleges respectively.

One of the fundamental assumptions of the CBAM model is that progression of the LoU is a function of time. This programme had been legally mandated for seven years at the time of data collection (June 1993-January 1994). For the early adopter colleges (A \& C) the programme had been in operation for 10 and nine years respectively. Furthermore. Hall and Hord (1987) maintained that over time, individuals develop their own patterns of using an innovation which works for them and that proficiency (levels of use at or above routine use) in using an innovation is a function of time.

This view was supported by the findings of this study for LoU on teaching for holistic nursing and developing independent learning skills. However, on teaching for $\mathrm{CHC}$ as well as teaching for critical thinking, proficiency had not been achieved by 26 and 22 nurse educators respectively. In addition, a number of nurse educators $(n=11)$ stated that they were not teaching for producing nurses capable of rendering $\mathrm{CHC}$.

The findings pertaining to the presence of non-users at using educational institutions have been documented elsewhere. Hall and Loucks (1977) reported that, at schools where the teachers were supposed to have been using individualised instruction, $20 \%$ were not using such teaching in mathematics and $26 \%$ were not using it in reading. Hall and Loucks wamed educational researchers about the tacit acceptance of use, simply because a "school" or "university" is supposed to be have adopted a particular innovation.

These results raised considerable concern for the investigator. After all, producing nurses capable of rendering comprehensive health care was one of the major reasons for the establishment of the CBNP (Searle, 1983; Uys, 1991; Van Huysstoen, 1989). Why then would nurse educators at three out four nursing colleges still be functioning at or below mechanical level of use almost a decade past legislated adoption?

It was assumed that there was a common perception and interpretation of the concept teaching for $\mathrm{CHC}$ at South African nursing colleges. This proved to be a grave 


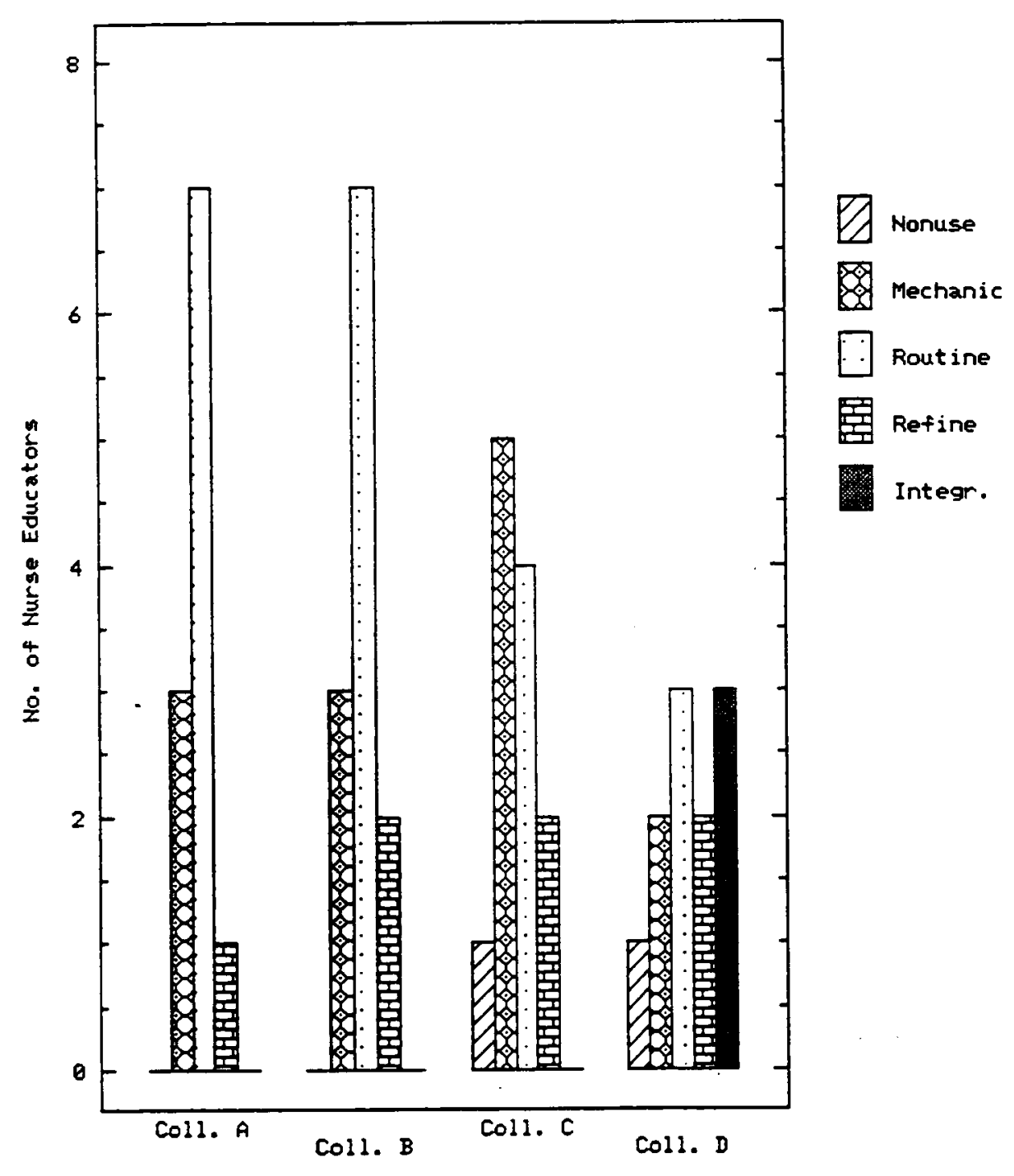

FIGURE 4: Variations between Colleges on Levels of Use on Developing Independent Learning Skills

miscalculation on the part of the investigator. Various interpretations and meanings of the term emerged as the study progressed. The various meanings and interpretations of the concept "teaching for CHC" were (a) health care rendered to individuals and families within the context of their communities, (b) same as holistic nursing, but much more comprehensive, (c) utilising general- , psychiatric-, community health nursing and midwifery skills in caring for individuals, families and communities, and (d) multidisciplinary approach to health care. Similar results were reported by Shipman and colleagues (cited in Dalton, 1988) in a study examining the implementation of the Keele Integrated Studies Project in UK schools. They found that although the project was perceived as consisting of three related elements of integrated subject matter, inquiry approach to teaching and team teaching, the project workers, teachers and local education authorities had different perceptions of what these three aspects meant. Based on their study's findings, Shipman and colleagues concluded that impact studies based on stated programme objectives under such circumstances were a waste of time. components of the CBNP, would be premature at this stage.

Implementation of two of the four major components of the $\mathrm{CBNP}$ needs to be facilitated. Explicit interpretations of the operational meaning of teaching for "producing nurses capable of rendering $\mathrm{CHC}$ and critical thinking" are required from the programme planners. This needs to be work-shopped with nurse educators to ensure understanding and ownership. Nurse educators must know what it is that they are supposed to be doing differently and how this can be achieved.

\section{REFERENCES}

Cameron, H. (1991). Effect of inservice training on implementation of a health curriculum in Nova Scotia, Canada. Joumal of School Health, 61(3), 131-135.

Dalton, T. H. (1988). The challenge of curriculum inneyation: A study of ideology and practice. Philadelphia: Farmer Press.

Debeauvais, M. (1981). Foreword. In R. S. Adams \& D. Chen, The process of educational innoyation: An intemational perspective (pp. ix-xi). London: Kogan Page.

Filkins, J. (1986, Feb. 12-18). Introducing change. Nursing Times, 82.(7), 26, 29-30.

Gibbs, A. (1991). Cultural and political limitations within a rational approach towards educational change. Joumal of Advanced Nursing 16, 182-186.

Hall, G. E., \& Hord, S. (1987). Change in Schools. Albany, NY : State University of New York Press.

Timing of adoption by an institution does not effect differences in how individuals perceive their own behaviours and skills in relation to implementing a legally mandated educational programme.

Global and general guidelines, although commendable in terms of the amount of freedom they give nurse educators in deciding what to do with an innovation, present a problem in cases where there are national educational objectives to be attained. This became very apparent with the diversity in the interpretations of the concept comprehensive health care encountered in this study. The same can be said of teaching for critical thinking. Although consensus is high in terms of its desirability, authorities in this field do not always agree as to what the term means.

In the light of the large number of nurse educators rated at or below mechanical LoU on teaching for CHC $(n=26)$ and critical thinking $(n=22)$, it is concluded that impact studies aimed at assessing outcomes on these
Hall, G. E., \& Loucks, S. F. (1977). A developmental model for determining whether the treatment is actually implemented. American Research Journal. 14(3), 263 - 276.

Hall, G. E., Loucks, S. F., Rutherford, W. L., \& B. W. Newlove. (1975). Levels of use of the innovation: A framework for analyzing innovation adoption. Lournal of Teacher Education. 26(1), 52-56.

Hord, S. (1987). Eyaluating educational innovation. London: Croom Helm.

Loucks, S. F., Newlove, B. H., \& Hall, G. E. innovation: A manual for trainers. interviewers and raters (Report No. 3013). Austin: The University of Texas at Austin, Research and Development Center for Teacher Education. (1975). Measuring levels of use of the 
Rispel, L. \& Motsei, M. (1988, July) Nursing in South Africa: Exploring nurses' opinions on controversial issues. Paper presented at the ASSA conference

Ross, J. G., Luepker, R. V., Nelson, G. D., Saavedra, P., \& Hubbard, B. M. (1991). Teenage health teaching modules: Impact of teacher training on implementation and student outcomes. Journal of Health Education 61(1), 31-34.

Searle, C. (1983). New dimensions: Nursing education in the post-secondary system in the Republic of South Africa. Curationis. 6 4-9.

Sheehan, J. (1990). Investigating change in a nursing context. Lournal of Advanced Nursing 15 819-824.

South African Nursing Council. (1985, Feb.). R 425:-Regulations relating to approval and the minimum requirements for the education and training of a nurse (general psychiatric and community) and midwife leading to registration. Pretoria: SANC.
Stevens, B. J. (1979). Nursing theory: Analysis. application evaluation. Boston: Little \& Brown.

Uys, L. R. (1991). Nursing Education. In L R. Uys \& W. J. Kotze' (Eds.) State of the att of nursing: A centenary publication (pp. 133-145). Pretoria: SANA.

Van der Merwe, A. S. (1989, September). A perspective from the nursing college of the Orange Free State. A paper presented at a symposium entitled Voorwaarts: "N D4 perspektief. Hosted by Ann Latsky nursing college.

Van Huyssteen, M. C. (1989, September). Die rasionaal agter die instelling van die vier jaar geintegreerde kurses wat lei tot registrasie by die Suid Afrikaanse Raad op Verpleeging as verpleegkundige en vroedvrou. A paper presented at a symposium entitled Yoocwaarts: 'ND4 perspektief. Hosted by Ann Latsky nursing college.

\section{ACKNOWLEDGEMENTS}

This study was conducted with the assistance of the University of Natal's research grant. The researcher would like to thank the nurse educators who participated in this study and Professor LR Uys for her invaluable comments.

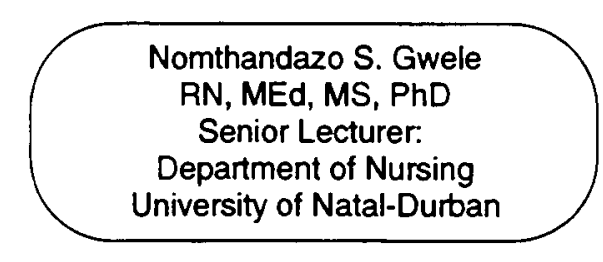

